\title{
Association of Oral Health and Systemic Diseases in the Elderly
}

\author{
Manjit Talwar, Gaurav Malik, Suresh Sharma, Atul Sachdev, Kirti Chaudhry
}

\begin{abstract}
Introduction: Oral health may have an impact on general health with clinical implications.
\end{abstract}

Objective: To assess association of oral health with systemic diseases in the elderly.

Materials and methods: A cross-sectional study was conducted in 232 elderly subjects (above 50 years) who visited the geriatric medicine OPD at Government Medical College and Hospital, Chandigarh. Oral examination was conducted using the WHO Oral Assessment Form (1997). Written informed consent was taken. Patients were grouped according to their systemic health into six groups: Healthy elderly (group 1), hypertension and coronary artery disease (group 2), chronic obstructive pulmonary disease (group 3), diabetes (group 4), diabetes and hypertension (group 5) and hypertension (group 6).

Results: Average DMFT for coronal caries in the six groups was $23.8,21.24,22.15,22.58,17.83,22.22$ respectively and root caries $22.04,18.05,19.46,14.90,14.75,18.62$. Periodontal status was assessed by recording the CPI score and attachment loss. Chi-square test was applied, a significantly $(p<0.05)$ higher CPI score was recorded for groups 2, 3, 6 compared to group 1 while attachment loss was significantly $(p<0.05)$ higher in diabetics (group 4) compared to group 1. Applying the Z-test for proportions a significantly $(p<0.05)$ higher number of group 1 edentulous subjects were using upper/lower complete dentures as compared to groups 4 and 5 .

Conclusion: Findings of this study indicate an inverse relationship of periodontal health with systemic diseases in the selected sample but further research is needed with larger sample to authenticate the results.

Keywords: Systemic disease, Dental caries, Edentulousness, Periodontal disease.

How to cite this article: Talwar M, Malik G, Sharma S, Sachdev A, Chaudhry K. Association of Oral Health and Systemic Diseases in the Elderly. Int J Experiment Dent Sci 2013;2(1): 9-13.

Source of support: Nil

Conflict of interest: None declared

\section{INTRODUCTION}

A gradual transition in the population has occurred in India, with reduction in percentage of the child population (0-14 years) and increase in the percentage of the elderly $(+60$ years). Percentage of population aged 60 and above of the total population in India in the year 2010 was $7.5 \%{ }^{1}$ and the projected increase is $10.7 \%$ by $2021 .^{2}$ This has been attributed to improved health care facilities, sanitation, environmental and public health reforms, coupled with better hygiene and living conditions.
The Government Medical College and Hospital is located at Chandigarh which is a joint capital of the states of Punjab and Haryana. A large number of elderly patients visit the hospital daily. Oral health has an impact on quality of life, as it affects esthetics, chewing ability, speech, comfort and emotional well being. M any of these patients have multiple coexisting medical problems, consume multiple medications for chronic systemic conditions like cardiac disease, respiratory problems, hypertension, psychiatric illness which may cause xerostomia, that increases the risk for dental caries as well as periodontal disease. ${ }^{3} Y$ et another factor is the influence of disability due to systemic diseases that affects the ability to carry out oral hygiene practices and adversely influences the oral microbial flora.

The association of oral infections with systemic diseases is receiving increased interest in the research world. The link between oral microbial infections and systemic disease is not a new concept. Evidence from ancient Egyptian medicine suggests that general health of the body could be improved subsequent to tooth extractions. ${ }^{4} \mathrm{~A}$ ssyrians in the 7th century $B C$ proposed that oral health affects the rest of the body. ${ }^{5} \mathrm{~A}$ similar hypothesis was given by Hippocrates (460-377BC). In 1778 J ohn Hunter a surgeon from England wrote that diseases of the teeth are likely to produce diseases in the neighboring parts, may be with serious consequences. This association was not given much attention till 1800. In 1818 B enjamin Rush a doctor from Pennsylvania recognized the focal infection theory, according to which oral infections caused inflammation in distant sites of the human system. In 1879, WD M iller from the University of Pennsylvania Dental School travelled to Berlin and at Koch's Institute looked into the relationship between oral bacteria and systemic diseases. In a series of articles published by M iller in 1891 he stated that pathogenic germs from the oral cavity produced disorders of the body. ${ }^{4}$

Studies have shown the oral-systemic connection. People with certain cardiac conditions, coagulation abnormalities and those with artificial joints are thought to be vulnerable to some of the microbes that live in the oral cavity. ${ }^{6-11}$ Periodontal disease affects the status of diabetes. ${ }^{12,13}$ M ost of the evidence is based from epidemiological studies. The present study was carried out in the elderly to assess if there is any association between oral health and systemic diseases. 


\section{MATERIALS AND METHODS}

The study was conducted on elderly patients visiting the geriatric medicine OPD at Government Medical College and Hospital, Chandigarh. The OPD patients were diverse in terms of locality, age, education, though more or less of similar socioeconomic status. Locality wise they camefrom different states of north and central India. The age of these subjects ranged from 50 to +90 years.

\section{Selection of Subjects}

A random sample of 232 subjects was drawn from patients visiting the geriatric medicine OPD with systemic health problems during summer vacations, i.e. from mid M ay 2008 to mid July 2008 (within a period of 60 days). A crosssectional population-based survey was carried out. All subjects who participated in the study were using nonfluoridated dentifrice and there was no water fluoridation in the areas from where these patients came.

\section{Oral Examination}

Oral examination was conducted using the W HO Oral $\mathrm{H}$ ealth A ssessment Form (1997) ${ }^{14}$ for recording dental caries, periodontal disease and edentulousness. Income and medical history were recorded. All participants were on follow-up treatment in the OPD. Written informed consent was taken from all the participants. The geriatric medicine OPD is run 6 days a week by the Department of General M edicine.

One examiner (MT) did the oral examination. For the purpose of recording plane mouth mirror and CPI probe was used. Coronal and root caries were recorded on all teeth including third molars. Periodontal status was recorded on ten index teeth $11,16,17,26,27,31,36,37,46,47$.

\section{Statistical Analysis}

The subjects examined were divided into various groups depending on the systemic diseases. Dental caries (coronal and root), periodontal status (CPI score and attachment loss) and edentulousness were compared in the various groups. Summary statistics was calculated of DMFT for coronal and root caries. The association of CPI score and attachment loss for various groups was computed using Chi-square test taking healthy elderly as basis for comparison. Comparison of upper/lower arches for prosthetic status and prosthetic need was done using $Z$ test for proportions keeping healthy elderly as control group. The IB M SPSS statistics package version 20 was used for the analysis.

\section{RESULTS}

A total of 232 elderly subjects were examined and their medical history was recorded. The subjects were divided into six groups based on systemic diseases, they were having. Group I comprised of healthy elderly subjects (HE); group 2 had subjects with hypertension and coronary artery disease (HT + CAD); group 3 subjects had chronic obstructive pulmonary disease (COPD); group 4 subjects had diabetes; group 5 were those subjects with diabetes al ongwith hypertension $(\mathrm{D}+\mathrm{HT})$ and group 6 were subjects with hypertension (HT) as shown in Table 1.

A verage DM FT for coronal caries in the six groups was 23.8 (group 1), 21.24 (group 2), 22.15 (group 3), 22.58 (group 4), 17.83 (group 5), 22.22 (group 6) as shown in Table 1. Corresponding DM FT for root caries was 22.04, $18.05,19.46,14.90,14.75$ and 18.62, as shown in Table 2.

Periodontal status was assessed by recording CPI score and attachment loss. CPI score recorded gingival bleeding,

\begin{tabular}{|lccc}
\multicolumn{2}{c}{ Table 1: Summary of statistics for coronal caries in the various groups } \\
\cline { 2 - 4 } Groups & $\mathrm{N}=232$ & Number of subjects & Mean DMFT \\
\hline 1 Healthy elderly & 25 & 10.77 & 23.8 \\
2 Hypertension and coronary artery disease & 37 & 15.94 & 21.24 \\
3 Chronic obstructive pulmonary disease & 26 & 11.20 & 22.15 \\
4 Diabetes & 31 & 13.36 & 22.58 \\
5 Diabetes and hypertension & 36 & 15.51 & 17.83 \\
6 Hypertension & 77 & 33.18 & 22.22 \\
\hline
\end{tabular}

\begin{tabular}{|lccc}
\hline Table 2: Summary of statistics for root caries in the various groups \\
Groups & \multicolumn{2}{c}{ Number of subjects } & Mean DMFT \\
\cline { 2 - 3 } & $\mathrm{N}=232$ & 10.77 & 22.04 \\
1 Healthy elderly & 25 & 15.94 & 18.05 \\
2 Hypertension and coronary artery disease & 37 & 11.20 & 19.46 \\
3 Chronic obstructive pulmonary disease & 26 & 13.36 & 14.90 \\
4 Diabetes & 31 & 15.51 & 14.75 \\
5 Diabetes and hypertension & 36 & 33.18 & 18.62 \\
6 Hypertension & 77 & & \\
\hline
\end{tabular}


calculus and periodontal pockets. Recordings were done on 10 index teeth. Comparison of code 1, 2, 3, 4 of healthy elderly was done with groups having systemic disease (Table 3). There were significantly $(p<0.05)$ higher CPI scores in subjects with hypertension and coronary artery disease (group 2), chronic obstructive pulmonary disease (group 3) and hypertension (group 6) compared to the healthy elderly subjects. No statistically significant difference was seen between the healthy elderly (group 1) and groups 4, 5. A ttachment loss recorded the destruction of periodontal attachment. A ttachment loss was significantly $(p<0.05)$ higher in diabetics (group 4) compared to healthy elderly (group 1) as shown in Table 4.

Prosthetic status was recorded, code 0 for no prosthesis, code 1 for bridge, code 2 for more than one bridge, code 3 for partial denture, code 4 for bridge and partial denture and code 5 for full removable denture. For all the groups, code $1,2,4$ recorded a score of zero. $Z$ test for proportions was applied to study the prosthetic status for maxillary and mandibular arches, as shown in Table 5. Comparison of the elderly with systemic diseases (groups $2,3,4,5,6$ ) with healthy elderly (group 1) showed a higher percentage of elderly with systemic disease were not using any prostheses (Table 5). There was no statistically significant difference between the groups in use of partial dentures (Table 5). Forty percent of healthy elderly were using full removable upper/lower dentures, $21.6 \%$ in group 2, 30.7\% in group 3, $16.1 \%$ in group $4,16.6 \%$ in group 5 and 27.2 in group 6. In patient with diabetes (group 4) and diabetes with hypertension (group 5) the use of upper and lower prostheses was less compared to the healthy elderly. The percentage of elderly subjects, who were edentul ous in the six groups was $44 \%$ (group 1), 35.13\% (group 2), 31.03\% (group 3), $22.58 \%$ (group 4), $19.44 \%$ (group 5) and $40.25 \%$ (group 6) (Table 7). L east number of subjects in group 1 needed upper/ lower prosthesis (Table 6). Though the percentage of edentulous subjects was highest in the healthy elderly, use of dentures was also more prevalent.

\section{DISCUSSION}

A verage DMFT ranged from 17.83 to 23.8 for coronal caries, 14.75 to 22.04 for root caries and edentulousness

\begin{tabular}{|c|c|c|c|c|c|c|c|c|c|}
\hline Groups & $\begin{array}{l}\text { No. of subjects } \\
(\mathrm{n}=232)\end{array}$ & $\begin{array}{l}\text { Code } 0 \\
\text { Healthy }\end{array}$ & $\begin{array}{c}\text { Code } 1 \\
\text { Bleeding }\end{array}$ & $\begin{array}{l}\text { Code } 2 \\
\text { Calculus }\end{array}$ & $\begin{array}{c}\text { Code } 3 \\
\text { Pocket } 4-5 \mathrm{~mm}\end{array}$ & $\begin{array}{c}\text { Code } 4 \\
\text { Pocket } 6 \mathrm{~mm}\end{array}$ & $\begin{array}{c}\text { Chi-square } \\
\left(\chi^{2}\right)\end{array}$ & df & $p$-value \\
\hline 1 & Healthy elderly $(n=25)$ & 4 & 12 & 28 & 17 & 3 & - & - & - \\
\hline 2 & Hypertension + CAD $(n=37)$ & 6 & 21 & 64 & 22 & 0 & 7.553 & 3 & $0.049^{*}$ \\
\hline 3 & $\operatorname{COPD}(n=26)$ & 7 & 9 & 21 & 37 & 0 & 11.485 & 3 & $0.009^{*}$ \\
\hline 4 & Diabetes $(n=31)$ & 3 & 13 & 53 & 49 & 8 & 4.374 & 3 & 0.224 \\
\hline 5 & Diabetes + HT $(n=36)$ & 26 & 13 & 63 & 30 & 3 & 3.155 & 3 & 0.368 \\
\hline 6 & HT $(n=77)$ & 16 & 8 & 135 & 62 & 10 & 19.167 & 3 & $0.0001^{*}$ \\
\hline
\end{tabular}

*Significant (all associations with health elderly); Code 0 not included for association as it did not represent disease

Table 4: Comparison of periodontal status: Attachment loss for the five groups with the health elderly

\begin{tabular}{|c|c|c|c|c|c|c|c|c|c|}
\hline Groups & $\begin{array}{l}\text { No. of subjects } \\
n=232\end{array}$ & $\begin{array}{l}\text { Code } 0 \\
0-3 \mathrm{~mm}\end{array}$ & $\begin{array}{l}\text { Code } 1 \\
4-5 \mathrm{~mm}\end{array}$ & $\begin{array}{l}\text { Code } 2 \\
6-8 \mathrm{~mm}\end{array}$ & $\begin{array}{l}\text { Code } 3 \\
9-11 \mathrm{~mm}\end{array}$ & $\begin{array}{l}\text { Code } 4 \\
12 \mathrm{~mm}\end{array}$ & $\begin{array}{c}\text { Chi-square } \\
\qquad\left(\chi^{2}\right)\end{array}$ & $d f$ & $\mathrm{p}$-value \\
\hline 1 & Healthy elderly $(n=25$ ) & 14 & 29 & 17 & 4 & 0 & - & - & - \\
\hline 2 & $H T+C A D(n=37)$ & 31 & 44 & 35 & 5 & 1 & 1.447 & 3 & 0.47 \\
\hline 3 & $\operatorname{COPD}(n=26)$ & 22 & 23 & 25 & 2 & 0 & 2.883 & 2 & 0.237 \\
\hline 4 & Diabetes $(n=31)$ & 20 & 47 & 57 & 2 & 0 & 7.403 & 2 & $0.025^{*}$ \\
\hline 5 & Diabetes + HT $(n=36)$ & 58 & 45 & 28 & 5 & 1 & 0.779 & 3 & 0.86 \\
\hline 6 & $\mathrm{HT}(\mathrm{n}=77)$ & 61 & 99 & 61 & 10 & 1 & 0.606 & 3 & 0.96 \\
\hline
\end{tabular}

*Significant (all associations with health elderly); Code 0 not included for association as it did not represent disease

Table 5: Prosthetic status for the maxillary and mandibular arches in the various groups

\begin{tabular}{|c|c|c|c|c|c|c|c|c|c|c|c|c|c|}
\hline & \multirow[t]{2}{*}{ Groups } & \multicolumn{2}{|c|}{$\begin{array}{c}\text { Code } 0 \\
\text { No prosthesis }\end{array}$} & \multicolumn{2}{|c|}{ Upper (U) } & \multicolumn{2}{|c|}{ Lower (L) } & \multicolumn{2}{|c|}{$\begin{array}{c}\text { Code } 3 \\
\text { Partial denture }\end{array}$} & \multicolumn{2}{|c|}{ Upper (U) } & \multicolumn{2}{|c|}{ Lower (L) } \\
\hline & & U & $\mathrm{L}$ & $Z$ test & $\mathrm{p}$-value & $Z$ test & $p$-value & $U$ & $\mathrm{~L}$ & Z-test & $p$-value & Z-test & $p$-value \\
\hline 1 & Healthy elderly $(n=25)$ & 5) 13 & 13 & - & - & - & - & 2 & 2 & - & - & - & - \\
\hline 2 & $H T+C A D(n=37)$ & 27 & 27 & -1.69 & 0.090 & -1.69 & 0.090 & 2 & 3 & 0.39 & 0.693 & -0.02 & 0.988 \\
\hline 3 & $\operatorname{COPD}(n=26)$ & 17 & 17 & -0.98 & 0.328 & -0.98 & 0.328 & 1 & 1 & 0.63 & 0.530 & -0.63 & 0.530 \\
\hline 4 & Diabetes $(n=31)$ & 23 & 24 & -1.75 & 0.081 & -2.03 & $0.042^{*}$ & 2 & 2 & 0.22 & 0.825 & 0.22 & 0.825 \\
\hline 5 & Diabetes + HT $(n=36)$ & 28 & 30 & -2.12 & $0.034^{*}$ & -2.66 & $0.008^{*}$ & 2 & 1 & 0.37 & 0.713 & 0.86 & 0.390 \\
\hline 6 & $\mathrm{HT}(\mathrm{n}=77)$ & 54 & 53 & -1.61 & 0.108 & -1.49 & 0.136 & 1 & 3 & 1.20 & 0.23 & 0.70 & 0.483 \\
\hline
\end{tabular}

${ }^{*}$ S ignificant using Z test for proportions. All comparisons made with healthy elderly (group 1 ) 


\begin{tabular}{|c|c|c|c|c|c|c|c|c|c|c|c|c|c|}
\hline & \multirow[t]{2}{*}{ Groups } & \multicolumn{2}{|c|}{$\begin{array}{c}\text { Code } 0 \\
\text { No prosthesis } \\
\text { needed }\end{array}$} & \multicolumn{2}{|c|}{ Upper (U) } & \multicolumn{2}{|c|}{ Lower (L) } & \multicolumn{2}{|c|}{$\begin{array}{l}\text { Code } 2 \\
\text { Need for } \\
\text { multiunit } \\
\text { prosthesis }\end{array}$} & \multicolumn{2}{|c|}{ Upper (U) } & \multicolumn{2}{|c|}{ Lower (L) } \\
\hline & & U & $\mathrm{L}$ & Z-test & p-value & Z-test & $p$-value & U & $\mathrm{L}$ & Z-test & $p$-value & Z-test & $p$-value \\
\hline 1 & Health elderly $(n=25)$ & 6 & 5 & - & - & - & - & 6 & 8 & - & - & - & - \\
\hline 2 & $\mathrm{HT}+\mathrm{CAD}(\mathrm{n}=37)$ & 10 & 10 & -0.27 & 0.788 & -0.65 & 0.516 & 14 & 16 & -1.18 & 0.236 & -0.91 & 0.364 \\
\hline 3 & $\operatorname{COPD}(n=26)$ & 9 & 5 & -0.84 & 0.401 & 0.07 & 0.945 & 5 & 9 & 0.41 & 0.679 & -0.20 & 0.843 \\
\hline 4 & Diabetes $(n=31)$ & 9 & 9 & -0.43 & 0.670 & -0.79 & 0.429 & 13 & 15 & -1.46 & 0.145 & -1.27 & 0.206 \\
\hline 5 & Diabetes + HT $(n=36)$ & ) 14 & 11 & -1.26 & 0.207 & -0.95 & 0.341 & 7 & 13 & 0.42 & 0.673 & 0.33 & 0.738 \\
\hline 6 & $\mathrm{HT}(\mathrm{n}=77)$ & 21 & 21 & -0.33 & 0.742 & -0.77 & 0.443 & 23 & 25 & -0.59 & 0.558 & -0.04 & 0.965 \\
\hline
\end{tabular}

All associations were nonsignificant $(p>0.05)$. All comparisons made with healthy elderly (group 1 )

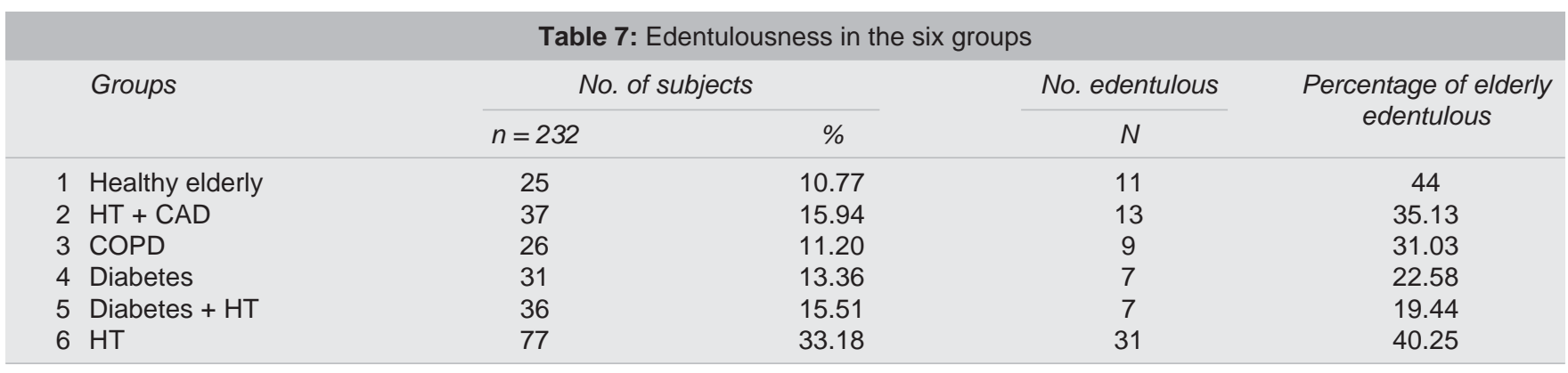

from 19 to $44 \%$. B oth edentulousness and dental caries was high in this population regardless of systemic health. A study from south India reported a DM F index of $13.5 .{ }^{15}$ The high DM FT in this population regardless of systemic health could possibly be due to lack of awareness and importance of oral health and the ability to access oral health services for restorative care. In this study the prevalence of coronal caries was found to be more than root caries. The findings are similar to a study by Thompson but contrasting to a study done by Shah and Sundaram where root caries comprised two-third of the lesions. ${ }^{3}$

CPI score was statistically significantly $(p<0.05)$ higher in patients with COPD, hypertension and those having hypertension and coronary artery disease compared to the healthy elderly (Table 3 ) indicating that subjects who were heal thy had better periodontal heal th compared to those who were medically compromised. In subjects with COPD use of inhalers causes dryness of the oral cavity, which alters the oral ecology making the subjects more prone to disease. ${ }^{16}$

A ttachment loss was higher in the elderly with systemic diseases compared to the healthy elderly though this difference was not statistical ly significant except for subjects with diabetes (group 4) who had significantly $p<0.05$ higher attachment loss. Evidence of a bidirectional relationship between diabetes mellitus and periodontal disease comes from studies conducted worldwide though in different settings. Patients with periodontal disease have a 1.5- to 2fold greater risk of having fatal CV D compared to patients without periodontal disease. ${ }^{17,18}$ The concentration of glycated hemoglobin (a measure of diabetic control) was found to be elevated in people with type 2 diabetes and severe periodontal disease, in a study by Shlossman et al. ${ }^{17}$

Use of dentures (prosthesis) was higher in the healthy elderly compared to those with systemic diseases which could possibly be due to the fact that systemic health was a priority over oral health. While those who have good health, sought dental services and were wearing prosthesis. The healthy elderly comprised of those elderly who came for a routine checkup and investigations. It is possible that they had undiagnosed systemic disease which they may not have been aware of.

There are certain issues specific to the ageing population. The social support of these individuals undergoes a change like economic constraints, retirement, living alone, problem of transportation and ability to access health services. W ith ageing physiological decline occurs, there are coexisting chronic diseases, e.g. arthritis, hypertension, cardiac diseases, respiratory illness, etc. and intake of multiple medications which may cause adverse drug reactions (ADRs) and xerostomia. A ll these have an impact on oral health and utilization of dental services. Oral cavity of the elderly has been exposed to challenges during younger years. Exposure of dentine occurs with age, along with surface diversity because of metal, ceramic and composite restorations thereby increasing the surfaces available for bacterial adhesion. There is a specific preference of oral microbes to colonize certain surfaces in the oral cavity. e.g.: S. mutans for enamel, S. salivarius for oral mucosal 
Association of Oral Health and Systemic Diseases in the Elderly

surfaces. ${ }^{19}$ In the ageing population because of surface diversity, altered ecology and xerostomia the oral cavity is more prone to disease.

Though it is difficult to obtain a cause and effect between oral infections and systemic diseases because of several confounding factors and oral infections are one of the many influences. The findings of this investigation are suggestive that healthy elderly subjects had better periodontal health and sought dental services more compared to those with systemic diseases. Association of periodontal health with diabetes and hypertension (group 2), chronic obstructive pulmonary disease (group 3) and diabetes (group 4) is significant. The elderly in the present study comprised of a heterogeneous population with wide variation in age, systemic health and educational status. As the sample size comprised of only 232 subjects it restricts the scope and ability to generalize the survey and further work in this direction is needed.

Occurrence of dental caries and edentul ousness was high in the elderly population studied at Chandigarh indicating a need for early planning of oral health services for the ageing population of the city and those visiting the hospital from the periphery.

\section{ACKNOWLEDGMENTS}

The authors thank Dr V ijay Chopra M DS Pedodontics and Preventive dentistry, Postgraduate Institute of Medical Education and Research, Chandigarh, for his valuable suggestions.

\section{REFERENCES}

1. Sample Registration System Statistical Report 2010. Office of the R egistrar G eneral, Government of India, New Delhi 2010:93102.

2. Population Projections for India and States 2001-2026. Report of the technical group on population projections constituted by the National Commission on Population M ay 2006. Office of the Registrar General and Census Commissioner, India.

3. Shah N, Sundaram KR. Impact of sociodemographic variables, oral hygiene practices, oral habits and diet on dental caries experience of Indian elderly: A community based study. Gerodontology 2004;21:43-50.

4. V ieira CLZ, Caramelli B. The history of dentistry and medicine relationship: Could the mouth finally return to the body? Oral Dis 2009;15:538-46.

5. Herzberg MC, M eyer MW. Effects of oral flora on platelets: Possible consequences in cardiovascular disease. J Periodontol 1996;67 (Suppl 10):1138-42.

6. Page RC. The pathobiology of periodontal disease may affect systemic diseases: Inversion of a paradigm. A nn Periodontol 1998;3(1):108-20.

7. Lowe GD. Etiopathogenesis of cardiovascular disease: Hemostasis, thrombosis and vascular medicine. A nn Periodontol 1998;3(1):121-26.
8. Genco RJ . Periodontal disease and risk for myocardial infarction and cardiovascular disease. Cardiovasc Rev Rep 1998;19(3): 34-40.

9. Dajani AS, TaubertKA, W ilson W, et al. Prevention of bacterial endocarditis: Recommendations by the A merican Heart Association. JADA 1997;128:1142-51.

10. Perkins $M$. The dangers of gum disease-Periodontitis and systemic disease. Dentistry (Indian Edition) 2011 Nov$\mathrm{Dec} ; 3(6): 5$.

11. FDI Policy Statement. The association between oral health and general health. Merging of association between oral, cardiovascular and cardiovascular health (2002) and dentistry and general health (1998). Revised version adopted by the General Assembly. 4th Sept 2009, Singapore.

12. Nishimura F, Takahashi K, K urihara M, Takashiba S, M urayama $Y$. Periodontal disease as a complication of diabetes mellitus. A nn Periodontol 1998;3(1):20-29.

13. Grossi SG, Genco RJ . Periodontal disease and diabetes mellitus: A two-way relationship. A nn Periodontol 1998;3(1):51-61.

14. W orld $\mathrm{H}$ ealth Organization. Oral health surveys basic methods (4th ed.) Geneva: World Health Organization, 1997.

15. Thomas S, Raja RV, K utty R, Strayer MS. Pattern of caries experience among an elderly population in South India. Int $D$ ent J 1994;44:617-22.

16. A zarpazhooh A, L eakeJ L. Systematic review of the association between respiratory disease and oral health. J Periodontal 2006;77(9):1465-82.

17. Shlossman M, Knowler WC, Pettitt DJ, Genco RJ. Type 2 diabetes mellitus and periodontal disease. J Am Dent Assoc 1990;121:532-36.

18. Grossi SG, Skrepcinski FB, DeCaro T, Zambon JJ, Cummins $D, G$ enco RJ . Response to periodontal therapy in diabetics and smokers. J Periodontol 1996;67(10 Suppl): 1094-102.

19. M arsh PD, Percival RS, Challacombe SJ. The influence of denture wearing and age on the oral microflora. J Dent Res 1992;71:1374-81.

\section{ABOUT THE AUTHORS}

\section{Manjit Talwar (Corresponding Author)}

A ssociate Professor, Department of D entistry, Government M edical College and Hospital, Chandigarh, India, e-mail: talwarmanjit7@ yahoo.in

\section{Gaurav Malik}

Senior R esident, Department of Dentistry, Government M edical College and Hospital, Chandigarh, India

\section{Suresh Sharma}

Professor, Department of Statistics, Panjab University, Chandigarh India

\section{Atul Sachdev}

Professor, Department of General M edicine, Government M edical College and Hospital, Chandigarh, India

\section{Kirti Chaudhry}

Senior Resident, Department of Dentistry, Government M edical College and Hospital, Chandigarh, India 